Rodolfo Andrade Gouveia Vilela ${ }^{1 *}$ Hildeberto Bezerra Nobre Junior ${ }^{2}$ José Marçal Jackson Filho ${ }^{3 * * * *}$ Ildeberto Muniz de Almeida ${ }^{4 * * * *}$

\section{Ameaças à proteção do trabalho: o caso da segurança em máquinas e equipamentos}

\author{
Threats to labor protection: the case of safety in machinery \\ and equipments
}

\footnotetext{
${ }^{1}$ Universidade de São Paulo, Faculdade de Saúde Pública, Departamento de Saúde Ambiental. São Paulo, SP, Brasil

2 Fórum Acidentes do Trabalho. São Paulo, SP, Brasil.

${ }^{3}$ Fundação Jorge Duprat Figueiredo de Segurança e Medicina do Trabalho, Centro Estadual do Paraná. Curitiba, PR, Brasil.

${ }^{4}$ Universidade Estadual Paulista “Júlio de Mesquita Filho", Faculdade de Medicina de Botucatu, Departamento de Saúde Pública. Botucatu, SP, Brasil.
}

\section{Contato:}

Rodolfo Andrade Gouveia Vilela

E-mail:

ravilela@usp.br

*Editor associado da RBSO.

*****ator Científico da RBSO.

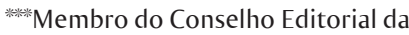
RBSO.
Vários sinais da conjuntura política e econômica brasileira mostram que uma onda conservadora está em movimento, colocando em risco direitos sociais e do trabalho instituídos pela Constituição Cidadã de 1988, entre eles a ameaça ao direito à proteção dos trabalhadores, como os expostos a riscos na utilização de máquinas e equipamentos, assegurado pela Norma Regulamentadora 12 (NR-12). Outras iniciativas patronais buscam, apoiadas por parlamentares, suspender, por exemplo, o anexo 3 da Norma Regulamentadora 15 (NR-15) sobre trabalho a céu aberto ${ }^{5}$ e reiniciar a discussão sobre o uso controlado do amianto, proposto por iniciativa extemporânea do Ex-Ministro do Trabalho e Emprego $\left(\mathrm{MTE}^{6}\right)$ que, pouco antes de sua exoneração, editou a Portaria n. 1.287, de 30 de setembro de 2015 (BRASIL, 2015a). Importante destacar as iniciativas favoráveis à intensificação da terceirização, cujas consequências à saúde dos trabalhadores e às relações de trabalho serão inevitáveis. Diante de contexto tão adverso, a unificação das centrais sindicais em torno da defesa da saúde dos trabalhadores se opera $^{7}$ especialmente em defesa da NR-12.

No que tange à desproteção dos trabalhadores no uso de máquinas e equipamentos, duas iniciativas parlamentares de análogo teor, ambas apoiadas por setores do empresariado, propõem a supressão da NR-12, que foi reformulada e aprovada pela Portaria n. 197/2010 do MTE (BRASIL, 2010): a primeira, o Projeto de Decreto Legislativo PDC 1.408/2013, do deputado federal Silvio Costa (PSC/PB); a segunda, o Decreto Legislativo DL 43/2015, de autoria do senador Cassio Cunha Lima (PSDB/PB). A segurança em máquinas e equipamentos encontra-se, dessa forma, sob ameaça política.

Em recente nota técnica, a ANAMATRA (Associação Nacional dos Magistrados da Justiça do Trabalho, 2015) se manifesta contra a admissibilidade do projeto PDC 1.408/2013. Série de argumentos contrários às inconsistências técnicas, jurídicas e políticas da proposta é apresentada, demonstrando a inconstitucionalidade do projeto. A ANAMATRA sustenta que a publicação da norma "constitui um marco fundamental na efetivação dos fundamentos constitucionais concernentes à dignidade da pessoa humana e ao valor social do trabalho de que tratam os incisos III e IV do artigo $1^{\circ}$ da Carta Magna”, além do artigo $7^{\circ}$, inciso XXII, que assegura como direito dos trabalhadores "a redução dos riscos inerentes ao trabalho, por meio de normas de saúde,

\footnotetext{
5 PDC 1.358/13, de autoria do deputado Domingos Sávio (PSDB/MG), susta a aplicação do Anexo 3 da NR 15 do MTE para as atividades sob céu aberto, que obriga a empresa a adotar medidas de proteção e pausas para evitar a sobrecarga térmica (BRASIL, 2013).

6 Atual Ministério do Trabalho e Previdência Social - MTPS.

7 Manifesto pode ser acessado em Fórum Nacional das Centrais Sindicais em Saúde do Trabalhador (2015).
} 
higiene e segurança" (grifo nosso). Dessa forma, conclui-se que a supressão da NR-12 fere a Constituição Federal, que "assegura ambiente de trabalho seguro e saudável aos trabalhadores".

Na mesma linha, em 15/4/2014, o Ministério Público do Trabalho (MPT), por meio de nota técnica, recomendou ao ministro do trabalho manter a NR-12 apesar das pressões de setores empresariais que buscavam o esvaziamento do processo tripartite e defendiam a suspensão da norma (BRASIL, 2014).

As duas propostas legislativas desconsideram os enormes custos aos trabalhadores vítimas de acidentes e às suas famílias, assim como os enormes custos financeiros e sociais cobertos pela Previdência Social e pelo Sistema Único de Saúde (SUS) (MELO, 2011) em decorrência de acidentes de trabalho envolvendo máquinas. Mesmo na vigência da NR-12, dados oficiais da Previdência Social, com base nas Comunicações de Acidentes de Trabalho (CAT), reconhecidamente subnotificadas e de alcance restrito a uma parcela do mercado formal, mostram que as máquinas e equipamentos, entre 2011 e 2013, estiveram envolvidas em 221.843 ocorrências, cerca de $17 \%$ do total de acidentes registrados no período. Nesses números estão incluídas cerca de 41.993 fraturas, equivalentes a 270 casos por semana. Mais grave ainda são as 13.724 amputações, ou 12 ocorrências desse tipo por dia, e 601 óbitos, o que representa um óbito a cada dia e meio de trabalho (BRASIL, 2015b).

Os principais argumentos defendidos pelos empresários e parlamentares que lutam pela supressão da NR-12 são: excessivo poder regulamentador do Ministério do Trabalho, linha de corte temporal para aplicação da norma, obrigações distintas entre fabricantes de máquinas e usuários empregadores, falta de critérios diferenciados para empresas de pequeno porte e desnecessidade da norma para a prevenção de acidentes.

Desqualificar a NR-12 por meio desses argumentos esconde a principal razão dos empregadores, a de se eximir da responsabilidade e dos custos necessários à prevenção. O pior é que a argumentação se funda em falsas premissas, que precisam ser revistas. Passemos em revisão esses argumentos e suas fragilidades.

\section{O poder regulamentador do Ministério do Trabalho}

Alega-se que, como a nova NR-12 propõe exigências que ultrapassam normas e requisitos legais vigentes em outros países, o MTE teria extrapolado seu limite regulamentador. $\mathrm{O}$ argumento se funda em dois pontos: $\mathrm{O}$ primeiro se baseia na comparação do Brasil com outros países, enquanto no segundo defende-se a transferência do poder regulamentador do Ministério do Trabalho para o parlamento; nessa perspectiva, qualquer processo normativo voltado à saúde e segurança do trabalho teria de ser remetido ao Congresso Nacional, espaço bastante favorável atualmente aos lobbies e interesses de grupos econômicos.

O argumento patronal reflete ainda uma posição de subalternidade em relação ao grau de proteção a que teria direito o trabalhador brasileiro. Segundo o raciocínio, em nenhuma hipótese nosso país poderia gozar de proteção superior ao que ocorre em outros países. O que se pretende, então, é que o país adote os piores padrões, que seriam, assim, formalmente reconhecidos como aceitáveis. Trata-se de um paradoxo, pois uma vez que a NR12 foi publicada em 2010, espera-se necessariamente que leve em conta a melhor tecnologia disponível nesse momento histórico, ou seja, espera-se que ela supere em alguns aspectos outras normas editadas em outros países em momentos anteriores. Importante ressaltar que a NR-12 foi formulada com base nas normas técnicas nacionais e internacionais, logo está em consonância com a normalização internacional sobre segurança de máquinas.

No tocante ao segundo ponto, que se refere ao poder regulamentador, o argumento fere a legislação vigente, pois contraria a Consolidação das Leis do Trabalho (CLT). A competência do Ministério do Trabalho para regulamentar os temas relacionados a saúde e segurança e saúde no trabalho decorre do cap. V, artigos 155 a 200 da CLT - Lei Federal 6.514/1977 (BRASIL, 1977). O artigo 186 é claro:

O Ministério do Trabalho estabelecerá normas adicionais sobre proteção e medidas de segurança na operação de máquinas e equipamentos especialmente quanto a proteção de partes móveis, distância entre estas, vias de acesso, etc. [...]

Ou seja, revogado o papel do poder executivo de regulamentar e atualizar as normas de saúde e segurança, conforme prevê a lei, cairia por terra todo processo de pactuação tripartite, todo processo normativo já consolidado, o que provocaria um estado de insegurança jurídica e retrocesso absoluto na área.

Transferir ao parlamento o processo de regulamentação é também um artifício que pretende romper com a trajetória tripartite de construção social negociada ${ }^{8}$ que ao longo das últimas décadas tem caracterizado a busca de aprimoramento da legislação vigente.

\footnotetext{
8 Todavia, algumas críticas podem ser dirigidas ao processo tripartite que se por um lado constitui mecanismo de diálogo social, por outro lado pode ser usado como mecanismo de controle do patronato sobre a produção normativa e, como consequência, sobre a ação de fiscalização. Há exemplos de soluções eficazes terem sido desconsideradas sem justificativa plausível, por não se chegar a um consenso. Pode-se citar, como ilustração, o caso do Anexo 1 da Norma Regulamentadora 17 (BRASIL, 2007), que trata do trabalho dos operadores de caixas desupermercado, no qual a atividade de empacotar não foi proibida a despeito dos danos possíveis aos trabalhadores.
} 
A nova NR-12 tem sua história ancorada no processo negocial que resultou em convenções coletivas no estado de São Paulo, como foi a negociação coletiva de máquinas injetoras de plástico (VILELA, 2001; SILVA, 2003), a convenção de proteção de máquinas de panificação, o programa de prevenção em riscos de prensas e similares, dentre outras que impulsionaram iniciativas para a disseminação dos avanços obtidos para todo o país. Paralelamente, esse movimento também incluiu iniciativas da Associação Brasileira da Indústria de Máquinas (ABIMAQ) que, a partir da década de 1990, via Associação Brasileira de Normas Técnicas (ABNT), busca harmonizar o mercado interno e preparar fabricantes para a disputa no mercado externo no tocante aos requisitos de projeto e de fabricação de máquinas e equipamentos. Na sua renovação, o grupo tripartite traduziu e reuniu em norma o que já se praticava nas indústrias e o que era de domínio da tecnologia.

Todo o processo de elaboração e revisão da norma, que durou de 2008 até 2013, ocorreu com discussão democrática, buscando o consenso tripartite. O primeiro texto foi submetido e aprovado depois de ampla consulta pública, que resultou na publicação da Portaria 197, em 24/12/2010 (BRASIL, 2010), estabelecendo cronograma e processo de implantação gradativa. Contudo, processo inverso pode ocorrer no Congresso, como foi a tentativa de votação em regime de urgência do PDC 43/2015, que esteve na iminência de suprimir a NR-12. A urgência só foi retirada depois de reação da sociedade, que conseguiu debater o assunto em audiência na Comissão de Direitos Humanos do Senado ${ }^{9}$. Tratar tal assunto em forma de urgência é clara tentativa de minimizar as chances de expressão e influência do ponto de vista dos trabalhadores nesse tipo de decisão.

\section{Linha de corte temporal - validade somente para máquinas e equipamentos fabricados a partir da vigência da Norma}

Os defensores da supressão da NR-12 alegam que os requisitos de segurança da norma deveriam ser aplicáveis seletivamente, valendo apenas para as máquinas fabricadas depois da data de vigência da norma.

Esse argumento patronal afronta o Princípio da Igualdade de Direitos consagrado na Constituição, pois criaria situações desiguais e injustas pela existência de duas categorias de trabalhadores: uma população de trabalhadores laborando em máquinas novas protegidas e outra, a grande maioria, operando máquinas velhas, obsoletas, desprotegidas, estando, portanto, exposta a riscos e situações mais críticas e vulneráveis a acidentes ${ }^{10}$.

Além disso, é importante destacar que a proteção de máquinas é estudada há mais de 100 anos. Diversas publicações já propunham a implantação de medidas de segurança, como barreiras fixas, barreiras móveis e dispositivos de intertravamento para evitar a exposição de partes do corpo dos trabalhadores a elementos móveis, partes giratórias, pontos entrantes e pontos de operação das máquinas (CALDER, 1899; MACHINERY'S REFERENCES, 1914).

No aspecto normativo, a proteção de máquinas é obrigação do empregador desde 1943, quando a CLT já prescrevia a obrigação de proteção de partes móveis. Em 1963 entra em vigor a Convenção 119 da Organização Internacional do Trabalho (OIT), que estabelece como obrigação dos empregadores implantar medidas pertinentes de segurança nas máquinas. Essa convenção só foi reconhecida oficialmente no país 30 anos depois, durante o período de redemocratização (BRASIL, 1991). A primeira versão da NR-12 foi publicada no bojo da portaria 3.214/1978, durante a ditadura militar, como forma de reação à pressão internacional e diminuir o elevado número de acidentes no país, qualificado, então, como o campeão mundial de acidentes de trabalho. Encontrava-se defasada após 32 anos, se considerarmos a versão publicada em 2010.

\section{Obrigações diferentes entre os fabricantes das máquinas e equipamentos e os usuários empregadores}

Segundo o discurso patronal, os fabricantes de máquinas deveriam garantir a segurança dos equipamentos e, portanto, se responsabilizar pela segurança do seu uso. Dessa forma, os empresários proprietários dos equipamentos não poderiam ser responsabilizados exclusivamente em caso de acidente. Tal argumento desconsidera a própria Convenção 119 da OIT, de 1963 (BRASIL, 1991), que prescreve a obrigação de os usuários obedecerem aos quesitos de segurança e sua responsabilidade no uso. Cabe ressaltar que essa diferenciação já está contemplada na redação da NR-12 que, no entanto, não exime os empregadores usuários dos equipamentos de sua obrigação de obedecer aos quesitos de segurança.

\footnotetext{
9 Inteiro teor da audiência pode ser acessado em Comissão de Direitos Humanos (2015).
}

10 É ilustrativa a conhecida rua Piratininga, na cidade de São Paulo, centro de comercialização de máquinas antigas e usadas sem dispositivos mínimos de segurança, conforme vídeo divulgado em reportagem televisiva que chama atenção para os riscos na aquisição dessas máquinas (GLOBO REPÓRTER, 2013) 


\section{Critérios diferenciados para empresas de pequeno porte}

No discurso patronal são alegadas dificuldades financeiras das pequenas empresas para arcar com os custos de adequação à norma. Esse argumento, todavia, deixa de considerar que a nova redação da NR-12, revisada em 2015, contemplou critérios diferenciados para as pequenas e microempresas, tanto em relação a prazos, em algumas situações, quanto às exigências de obrigações acessórias, menos rígidas para esse segmento empresarial.

Inquestionavelmente, o Estado deve prever linhas de crédito próprias para as Microempresas, Empresas de Pequeno Porte e Empresas Individuais de Responsabilidade Limitada, especialmente para a troca e/ou adequação das máquinas às diretrizes da NR-12, com juros mais favoráveis e com a redução do trâmite burocrático que dificulta o acesso ao crédito.

\section{A desnecessidade da norma: a segurança na dependência do treinamento, cuidado e atenção dos operadores}

Historicamente, os representantes das empresas procuram se eximir de responsabilidade em caso de acidentes, atribuindo-os ao comportamento inadequado, incorreto, dos trabalhadores: o chamado "ato inseguro". Os projetos de lei propostos se fundam nessa perspectiva, ou seja, caso "treinados" e "mais conscientes e atentos”, os trabalhadores não estariam expostos a riscos, nem sofreriam acidentes. Dessa forma, a segurança e prevenção não necessitariam de maior rigor normativo.

Esse argumento contraria princípios básicos da segurança, que deve associar medidas ativas, que dependem da adesão do trabalhador (como o uso de Equipamentos de Proteção Individual - EPI), e passivas, aquelas que agem independentemente do trabalhador e, portanto, mais eficazes. Desconsidera-se, também, que, em situação de risco potencial de lesão ou consequência grave, a prevenção não pode consistir apenas de medidas ativas. Privilegiando o sistema de gestão do comportamento (medidas ativas), abre-se mão da melhor prevenção (medidas passivas) e pavimenta-se o caminho para culpar as vítimas em caso de eventual acidente.

Nessa visão reducionista não são considerados a interação complexa do operador diante de vários constrangimentos presentes na situação de trabalho, nem o conhecimento básico de que apenas a atenção não é suficiente para garantir a segurança em uma máquina perigosa, tampouco o fato de que nenhum ser humano consegue manter um nível elevado de atenção durante longos períodos de tempo.

\section{Considerações finais}

Como evidenciado, a situação atual se caracteriza pelo retrocesso, operado pelos representantes do empresariado, no que tange à utilização de conhecimentos solidificados para a prevenção de acidentes com máquinas e equipamentos, contrariando sua própria posição anterior, sustentada no longo processo de negociação tripartite.

Aproveitando-se da onda conservadora no parlamento, as propostas apresentadas desrespeitam os princípios fundamentais da preservação da vida e do direito à saúde previstos na Carta Constitucional vigente e descartam os avanços tecnológicos incontestáveis que devem ser utilizados para a promoção e a defesa da cidadania de todos os brasileiros.

Por fim, resta-nos questionar se a propalada responsabilidade social, tão presente na ideologia empresarial difundida atualmente, resume-se apenas a seu discurso.

\section{Referências}

ASSOCIAÇÃO NACIONAL DOS MAGISTRADOS DA JUSTIÇA DO TRABALHO - ANAMATRA. Nota técnica: projeto de decreto legislativo - PDC No 1408/2013. Câmara dos Deputados, Brasília, DF, 08 set. 2015. Disponível em: <http://www.anamatra.org.br/uploads/Anexos_Noticias/nota-tecnica-nr-12.pdf>. Acesso em: 08 nov. 2015.

BRASIL. Lei $\mathrm{n}^{\circ}$ 6.514, de 22 DE dezembro de 1977. Altera o Capítulo V do Titulo II da Consolidação das Leis do Trabalho, relativo a segurança e medicina do trabalho e dá outras providências. Diário Oficial [da] União, Brasília, DF, 23 dez. 1977. 
BRASIL. Decreto legislativo no 232, DE 1991. Aprova o texto da convenção no 119, sobre proteção das máquinas, adotada na $47^{\mathrm{a}}$ Sessão da Conferência Internacional do Trabalho, da Organização Internacional do Trabalho - OIT, realizada em Genebra, em junho de 1963. Diário [do] Congresso Nacional, Brasília, DF, 16 dez. 1991. p. 26733.

. NR 17 - Anexo I da NR 17. Prevenção dos problemas de segurança e saúde relacionados ao trabalho dos operadores e operadoras de caixa. Brasília, DF: CNTC, 2007.

. Ministério do Trabalho e Emprego. Secretaria de Inspeção do Trabalho. Portaria SIT no 197 de 17 de

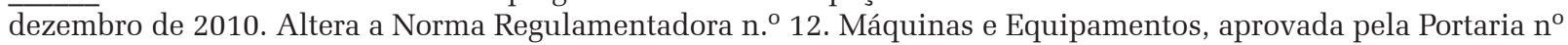
3.214, de 8 de junho de 1978. Diário Oficial [da] República Federativa do Brasil, Brasília, DF, 24 dez. 2010.

. Projeto de Decreto Legislativo PDC 1358/2013. Susta a aplicação do Anexo 3, da Norma Regulamentadora n 15 (NR 15), do Ministério do Trabalho e Emprego para as atividades sob céu aberto. Câmara dos Deputados, Brasília, DF, 29 out. 2013.

. Ministério Público do Trabalho. Procuradoria Geral do Trabalho - PGT. Nota Técnica do Ministério Público do Trabalho sobre a NR 12. Brasília, 2014. Disponível em: < http://www.prt4.mpt.gov.br/images/Ascom/2014/2304_ nota.pdf>. Acesso em: 08 nov. 2015.

. Portaria MTE $n^{\circ} 1.287$, de 30 de setembro de 2015(a). Institui a Comissão Especial para Debater o Uso do Amianto no Brasil. Diário Oficial [da] República Federativa do Brasil, Brasília, DF, 01 out. 2015a. p. 123.

. Secretaria de Inspeção do Trabalho. Nota informativa no 58/2015/CGNOR/DSST/SIT. Brasília, $2015 \mathrm{~b}$.

CALDER, J. The prevention of factory accidents. New York: Long Mans, 1899.

COMISSÃO DE DIREITOS HUMANOS - CDH. CDH debate segurança no trabalho em máquinas e equipamentos. 8 set. 2015. Disponível em: <https://www.youtube.com/watch?v=TSeOCTKCrmM>. Acesso em: 20 out. 2015.

FÓRUM NACIONAL DAS CENTRAIS SINDICAIS EM SAÚDE DO TRABALHADOR. Manifesto das centrais em defesa da saúde dos trabalhadores e trabalhadoras. 2015. Disponível em: < http://fetraconspar.org.br/documentos/ Manifesto_28_10.pdf>. Acesso em: 08 nov. 2015.

GLOBO REPÓRTER. Acidentes de trabalho. 19 abr. 2013. Disponível em: < https://www.youtube.com/ watch?v=uFi0ww5t61Y > . Acesso em: 21 out. 2015.

MACHINERY'S REFERENCES. Safeguards for Machine tools and Power Presses $N^{o} 140$. New York: The Industrial Press, 1914.

MELO, L. E. A. A previdência social e a luta contra os acidentes e doenças do trabalho no Brasil. Informe de Previdência Social, Brasília, v. 23. n. 7, p. 03-07, 2011. Disponível em: <http://www.previdencia.gov.br/arquivos/ office/3_110728-104424-440.pdf>. Acesso em: 08 nov. 2015.

SILVA, L. M. Negociação coletiva em saúde do trabalhador: segurança em máquinas injetoras de plástico. São Paulo em Perspectiva, São Paulo, v. 17, n. 2, p. 23-31, 2003.

VILELA, R. A. G. Negociação nas máquinas injetoras de plástico: prevenção e avanço nas relações de trabalho. Revista Brasileira de Saúde Ocupacional, São Paulo, v. 26, n. 97-98, p. 33-43, 2001. 